\title{
Actividades en AEMET del SAF de nowcasting para la era MTG
}

https://doi.org/10.31978/639-19-010-0.047

\author{
Miguel Ángel Martínez Rubio¹ (mmartinezr@aemet.es) \\ Xavier Calbet Álvarez ${ }^{1}$ (xcalbeta@aemet.es)
}

${ }^{1}$ AEMET / Dirección de Producción e Infraestructuras

\begin{abstract}
RESUMEN
Se describen los desarrollos que se están realizando en AEMET para la era METEOSAT Tercera Generación (MTG) dentro del SAF de nowcasting (NWC SAF). El programa MTG estará constituido por dos satélites geoestacionarios complementarios: MTG-I y MTG-S. El satélite MTG-I (Imaging) llevará a bordo los instrumentos FCI y LI (detector de rayos). FCI es el instrumento de toma de imágenes que contará con nuevos canales. MTG-S (Sounding) llevará a bordo los sondeadores hiperespectrales IRS (en el infrarrojo) y Sentinel-4 (UV/VIS).

El equipo de AEMET del NWC SAF ha propuesto el desarrollo de varios productos y servicios para MTG-I y MTG-IRS con el objetivo de aprovechar al máximo las sinergias entre todos los instrumentos de MTG.

El programa interno PGE00 que utiliza la interpolación 4D de perfiles del ECMWF en niveles híbridos y RTTOV-12.1 se ha usado para simular los canales de FCI y de IRS. Se describe uno de los primeros resultados en la investigación del uso del nuevo canal VIS0.9 de FCI para obtener la estructura espacial del contenido de agua precipitable total (TPW).
\end{abstract}

PALABRAS CLAVE: nowcasting; EUMETSAT; MSG; RTTOV; imágenes RGB; iSHAI; PGE00; SHAI.

\section{INTRODUCCIÓN}

En este artículo se describen los desarrollos que se están realizando en AEMET para la era MTG dentro del SAF de nowcasting. El programa MTG realizará la operación conjunta de una formación de dos satélites geoestacionarios complementarios: MTG-I y MTG-S. Cuando MTG esté operativo hacia el año 2025 se entrará en una edad de oro en la observación con satélites meteorológicos. En la figura 1 puede observarse como la evolución de los satélites METEOSAT desde la primera a la tercera generación supone una gran revolución.

METEOSAT Segunda Generación (MSG) fue el primer satélite geoestacionario en disponer de 12 canales ( 4 canales visibles y 8 canales IR). MSG ha sido superado actualmente por los satélites geoestacionarios de tercera generación HIMAWARI (JMA desde 2015) y la clase GOES-R (NOAA desde 2016) con 16 canales (6 canales visibles y 10 canales IR). Cuando MTG-I (Imaging) sea lanzado en 2021, llevará

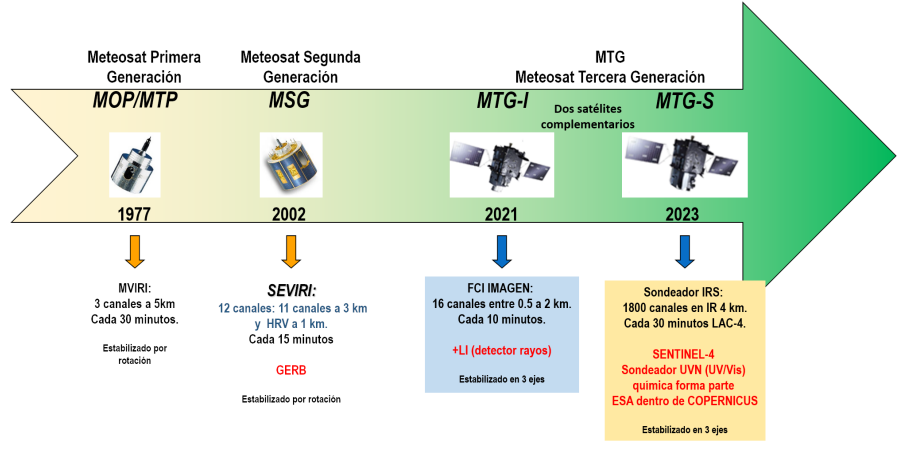

Figura 1. Evolución de satélites METEOSAT. 
a bordo los instrumentos FCI y LI (detector de rayos semejante al GLM de los satélites GOES-R). FCI es el instrumento de toma de imágenes que contará con nuevos canales e importantes mejoras en las resoluciones temporal y espacial. FCI observará también en 16 canales pero en ocho canales visibles y en ocho IR.

En 2023 se lanzará su compañero y complementario, el satélite MTG-S llevará a bordo dos sondeadores hiperespectrales: IRS (en el IR) y Sentinel-4 (en UV/VIS). MTG-S marcará el inicio de una nueva era en la observación desde órbita geoestacionaria. Aunque IRS no será el primer sondeador hiperespectral IR en órbita geoestacionaria, ya que la Agencia Meteorológica de China (CMA) ha lanzado en FY-4 el instrumento experimental GIIRS, sí será el más avanzado en resolución espectral, espacial y temporal. El sondeador IRS proporcionará el espectro en el IR y WV en 2 bandas con unos 1800 canales. El instrumento Sentinel-4, que forma parte del programa Copernicus de la Agencia Espacial Europea (ESA), obtendrá espectros en el visible y ultravioleta sobre una región centrada en Europa. Por esta razón la península ibérica y Canarias formarán parte de la región del mundo con mejor cobertura por satélites meteorológicos que haya habido nunca.

El reto es diseñar productos y algoritmos que exploren las sinergias entre todos los instrumentos de MTG. Como puede verse en la figura 2, el segmento terrestre tiene una parte centralizada con productos generados en la sede EUMETSAT (a los que se conoce como EUMETSAT Secretariat) y otra formada por los productos generados por la red de SAF. Dentro de la red de SAF, el NWC-SAF es un SAF especial que desarrolla software; por esta razón, NWC-SAF es el más cercano a los usuarios ya que se instala y opera en el lado de los usuarios de la EUMETCast.

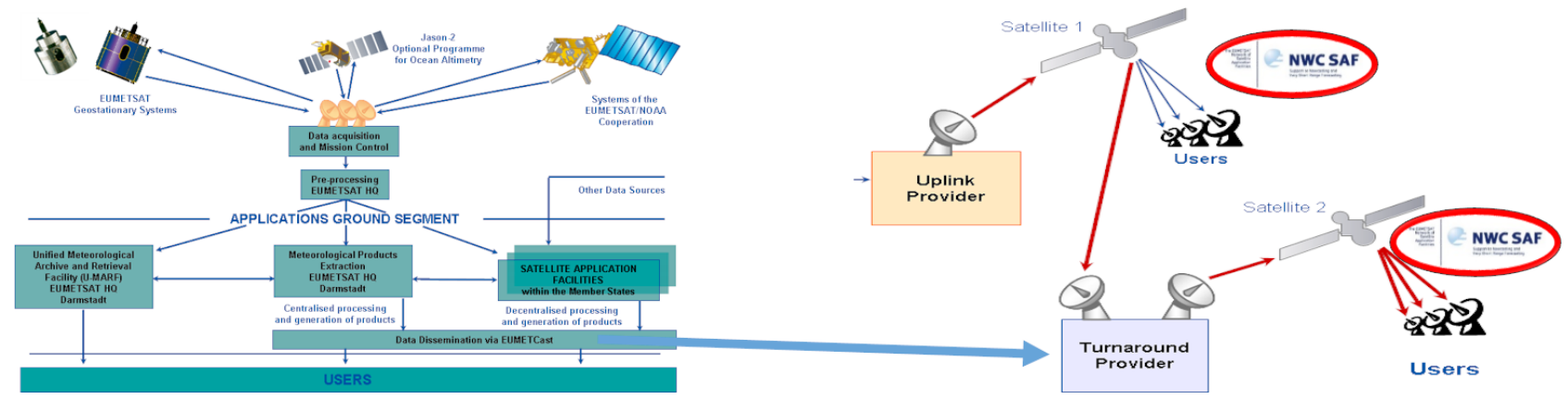

Figura 2. NWC SAF dentro del segmento terrestre de EUMETSAT.

Aprovechando los avances de MTG y que el software del NWC SAF es ejecutado localmente por los usuarios, el NWC SAF ha propuesto nuevos productos y servicios para aprovechar las sinergias de los diferentes instrumentos de MTG. Como los productos del NWC-SAF se generan localmente por los usuarios no hay restricciones en el ancho de banda, ni en el número ni en el tamaño de los productos. El usuario puede seleccionar la región de interés donde procesar usando sus propios modelos numéricos. Además, el software del NWC SAF para MTG será usado por otros SAF dentro de sus cadenas operativas.

En la Sección 2 se realiza una descripción de MTG-FCI y de cómo el programa interno PGE00 puede ser usado para simular los canales de FCI. Se describe también uno de los primeros resultados en la investigación del uso del nuevo canal VIS0.9 para obtener una estimación de la estructura espacial del contenido de agua precipitable total (TPW).

En la Sección 3 se realiza una descripción de IRS y de los productos y servicios propuestos. Estos son: a) quick IRS: preproceso de ficheros nivel 1. Se realizará la reconstrucción de los espectros de temperaturas de brillo (BT) a partir de las 300 componentes principales diseminadas y la posterior reproyección a regiones NWCSAF para canales prefijados, b) sSHAI para la obtención de perfiles de temperatura y humedad localmente con las BT de IRS del servicio quick-IRS y c) servicio sSHAI_ES para manejo y reproyección de los productos nivel 2 de EUMETSAT Secretariat (ES) a regiones de interés de los usuarios. 


\section{DESCRIPCIÓN DE MTG-FCI Y PLANES DEL NWC SAF}

FCI es el instrumento de toma de imágenes del programa MTG que contará con nuevos canales e importantes mejoras en las resoluciones temporal y espacial respecto a MSG. FCI tendrá una resolución temporal de 10 minutos (2,5 minutos en modo rapid scan). En la figura 3 se muestran los canales del instrumento MTG-FCI; FCI es el sucesor de SEVIRI en MSG y los canales nuevos se han marcado con *. La resolución espacial será de $1 \mathrm{~km}$ en los canales VIS e infrarrojo cercano y de $2 \mathrm{~km}$ en los canales IR; aunque FCI tiene cuatro canales en los que se realiza la observación en modo especial a doble resolución espacial pero en EUMETCast satélite solo estarán disponibles en resolución nominal.

Hay que destacar que en MTG-FCI será la primera vez que el conjunto completo de canales visibles esté disponible en el mismo satélite. Esto implica que FCI dispondrá del mejor conjunto de canales visibles en un instrumento de imágenes en órbita geoestacionaria.

Como preparación y validación de algoritmos de MTG-FCI y empezar a utilizar los canales nuevos, el software del NWC SAF ha sido migrado a los satélites Himawari y GOES-R en la versión 2018. En la figura 4 se muestra el producto iSHAI generado con Himawari.

\begin{tabular}{|c|c|c||}
\hline $\begin{array}{c}\text { Longitud de } \\
\text { onda central }\end{array}$ & $\begin{array}{c}\text { Resolución } \\
\text { espacial }\end{array}$ & $\begin{array}{c}\text { Modo alta } \\
\text { resolución }\end{array}$ \\
\hline \hline $0,44 \mu \mathrm{m}^{*}$ & $1,0 \mathrm{~km}$ & \\
\hline \hline $0,51 \mu \mathrm{m}^{*}$ & $1,0 \mathrm{~km}$ & \\
\hline $0,64 \mu \mathrm{m}$ & $1,0 \mathrm{~km}$ & $0,5 \mathrm{~km}$ \\
\hline \hline $0,86 \mu \mathrm{m}$ & $1,0 \mathrm{~km}$ & \\
\hline $0,91 \mu \mathrm{m}^{*}$ & $1,0 \mathrm{~km}$ & \\
\hline $1,38 \mu \mathrm{m}^{*}$ & $1,0 \mathrm{~km}$ & \\
\hline \hline $1,61 \mu \mathrm{m}$ & $1,0 \mathrm{~km}$ & \\
\hline \hline $2,25 \mu \mathrm{m}^{*}$ & $1,0 \mathrm{~km}$ & $0,5 \mathrm{~km}$ \\
\hline \hline $3,80 \mu \mathrm{m}$ & $2,0 \mathrm{~km}$ & $1,0 \mathrm{~km}$ \\
\hline \hline $6,30 \mu \mathrm{m}$ & $2,0 \mathrm{~km}$ & \\
\hline \hline $7,35 \mu \mathrm{m}$ & $2,0 \mathrm{~km}$ & \\
\hline \hline $8,70 \mu \mathrm{m}$ & $2,0 \mathrm{~km}$ & \\
\hline \hline $9,66 \mu \mathrm{m}$ & $2,0 \mathrm{~km}$ & \\
\hline \hline $10,50 \mu \mathrm{m}$ & $2,0 \mathrm{~km}$ & $1,0 \mathrm{~km}$ \\
\hline \hline $12,30 \mu \mathrm{m}$ & $2,0 \mathrm{~km}$ & \\
\hline \hline $13,30 \mu \mathrm{m}$ & $2,0 \mathrm{~km}$ & \\
\hline \hline
\end{tabular}

Figura 3. Canales de MTG-FCI.

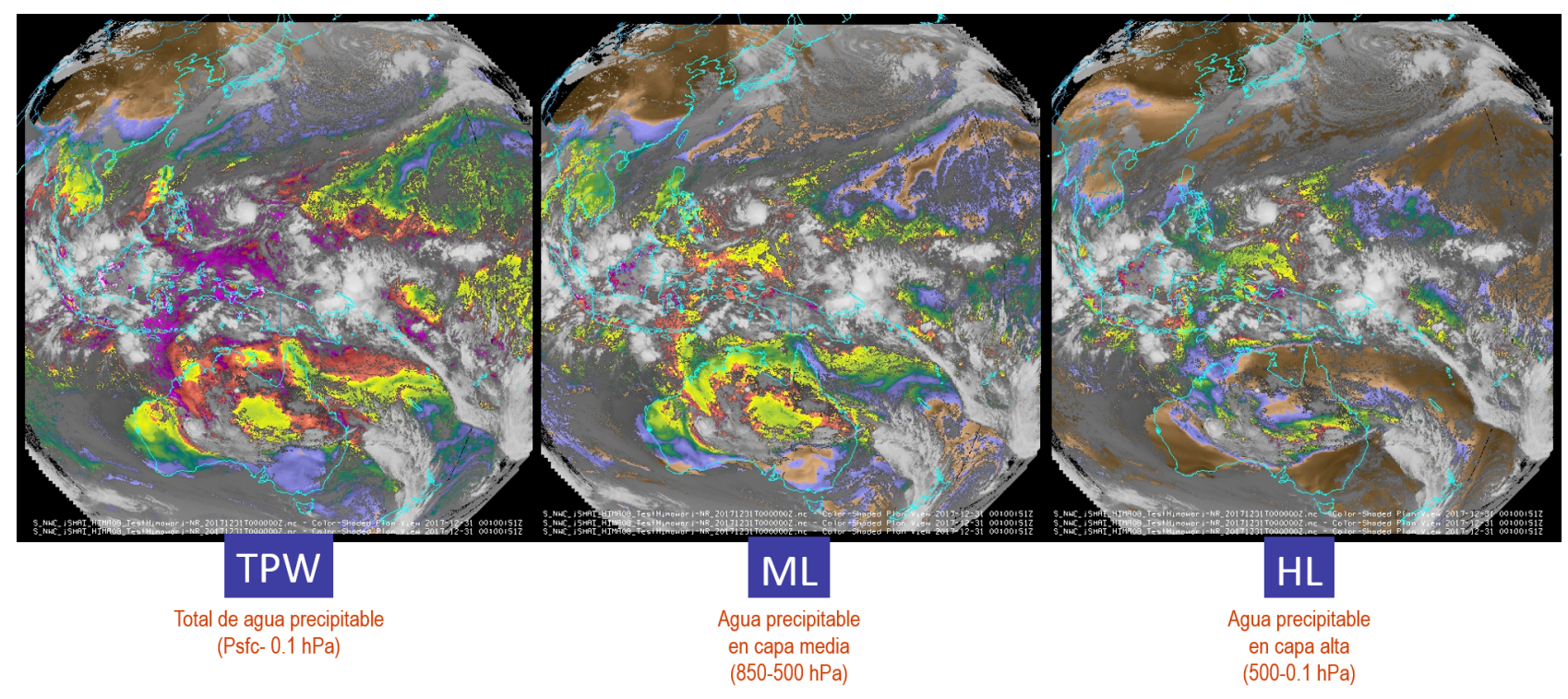

Figura 4. Ejemplo de iSHAI v2018 generado con datos de Himawari. 2017-12-31 a las $00 \mathrm{Z}$.

Aunque algunos de los canales nuevos están ya presentes en Himawari o GOES-R, el resto de nuevos canales y el uso conjunto de todos los canales solo puede simularse mediante programas de transferencia radiativa como RTTOV. El programa de AEMET PGE00 utiliza la interpolación 4D (vertical, temporal y espacial) de los perfiles del ECMWF en niveles híbridos y RTTOV-12.1 para simular los canales de MTG-FCI y MTG-IRS. PGE00 puede ser usado para la generación de imágenes sintéticas tanto en aire claro como en nubes. PGE00 usa como entrada ficheros GRIB del ECMWF en coordenadas híbridas con los perfiles ( $T, q$, ozono, CC, CLWC, CIWC); ver más detalles en (MARTínez y CALBEt, 2018a, 2018b). 
El canal VIS0.64 en el rojo junto con los nuevos canales VIS0.51 en el verde y VIS0.44 en el azul pueden ser usados para la generación de imágenes RGB color verdadero (truecolor). Esta RGB es útil para la discriminación entre nubes, polvo y humo. Cuando estos canales son corregidos (corrección scattering de Rayleigh) se obtienen imágenes con alto contraste que al estar más cercanas a la percepción del ojo humano serán las utilizadas en webs para el público en general. Pueden verse imágenes RGB «color-verdadero» corregidas con los satélites GOES-R y HIMAWARI en la web del SLIDER del CIRA( no hay planes de incluir esta corrección dentro de NWCSAF/GEO, este tiene que realizar el preproceso (lectura, conversión a radiancias y composición del mosaico de ficheros netCDF en que se realizará la diseminación del FCI) necesario para obtener las imágenes para una región de interés para la generación del resto de productos con FCI. Además, en NWCSAF/GEO se generan como ficheros temporales los parámetros necesarios para la corrección de Rayleigh (ángulos cenitales solar y del satélite). Por tanto, al menos para AEMET, el software del NWCSAF es un punto ideal donde realizar esta corrección. Aunque se utilice como base el software de otros (SMN de Australia, NOAA, etc.) habrá que generar parámetros y tablas LUT específicas para MTG-FCI. En la figura 5 se presenta una imagen RGB sintética «color-verdadero» MTG-FCI generada con PGE00 sin corrección de Rayleigh.

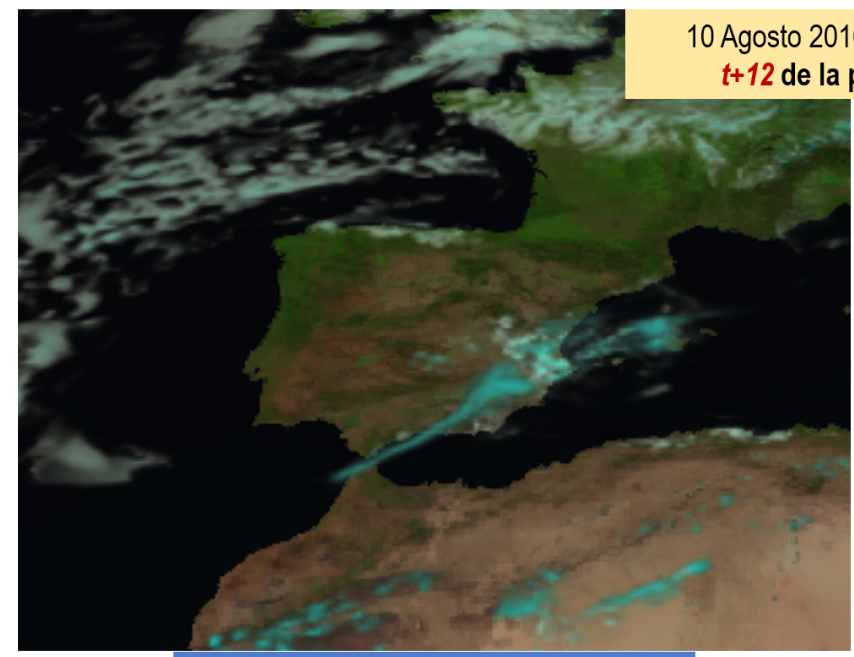

FCI RGB natural normalizada sintética

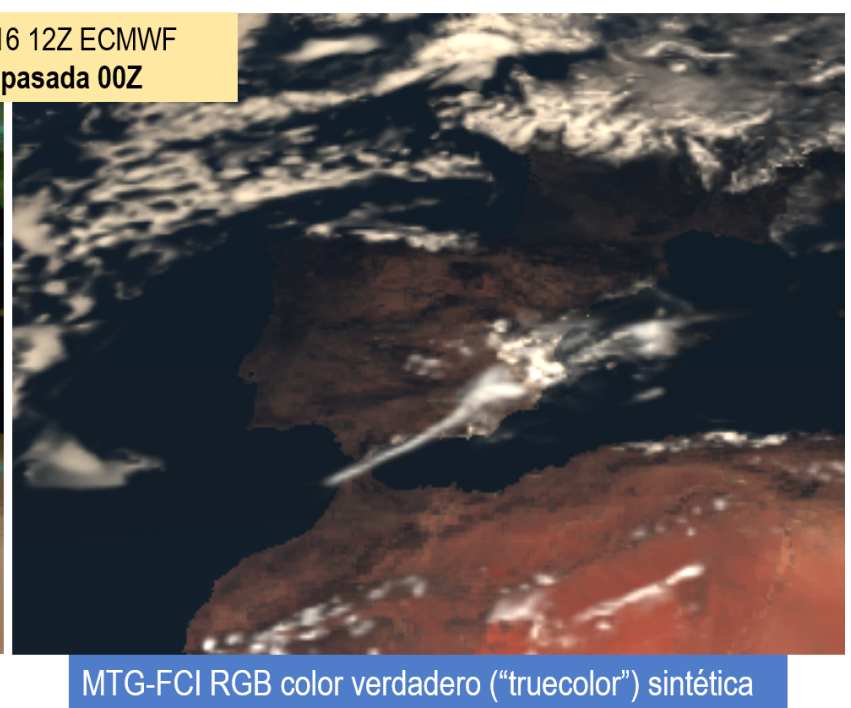

MTG-FCI RGB color verdadero ("truecolor") sintética

Figura 5. RGB sintéticas natural y color verdadero de FCI generadas con PGE00.

\subsection{Estudio preliminar para estimación de TPW usando el canal MTG-FCI VIS0.91}

El nuevo canal MTG-FCI VIS0.91 $\mu$ m es un canal absorción por vapor de agua en el visible y es la primera vez que estará presente en un instrumento en órbita geoestacionaria. La estimación de TPW usando este canal es de gran interés en la monitorización de la convección y en la validación del contenido de agua precipitable de los productos SHAI (que utilizan canales IR) al poderse obtener con alta resolución espacial $1 \mathrm{~km}$ y temporal cada 10 minutos. EUMETSAT y otros investigadores están desarrollando algoritmos para la obtención del TPW usando el canal VIS0.9 en el instrumento de imágenes de EPS-SG. Mientras se dispone de un algoritmo validado (que puede requerir años) se ha realizado un test de cara a disponer al menos de una estimación cualitativa de la estructura espacial y poderla usar por ejemplo en una imagen RGB.

Puede verse en la figura 6.d como la imagen sintética del canal VIS0.91 no se parece al campo TPW del ECMWF mostrado en la figura 6.c; esto se debe a que la absorción del vapor de agua es muy débil. La diferencia de las reflectancias entre VIS0.91 y VIS0.8 tampoco se parece al campo de TPW (no mostrada en la figura 6). Se han generado también las reflectancias sintéticas (en aire claro) usando los perfiles de temperatura del modelo en cada píxel y el valor medio del perfil de $q$ en cada nivel para los canales VIS09 y 
VIS08: denotados como VIS09 ${ }_{\text {mean_q }}$ y como VIS08 ${ }_{\text {mean_q }}$ y mostrados en las figuras 6.a y 6.b. Al usar la fórmula siguiente:

$$
\left(\log \left(\text { VIS09) }-\log \left(\text { VIS09 }_{\text {mean_q }}\right)\right)-\left(\log (\text { VIS08 })-\log \left(\text { VISO8 }_{\text {mean_q }}\right)\right)\right.
$$

se obtiene un campo que sí se asemeja al campo TPW del ECMWF. Este campo es el representado en la figura 6.f. Véase bucle en la web del NWC SAF en el hipervínculo.

Este tipo de estudios no era posible cuando se escribió la propuesta CDOP-3 del NWCSAF ya que no se disponía entonces de PGE00 con transferencia radiativa en los canales visibles.

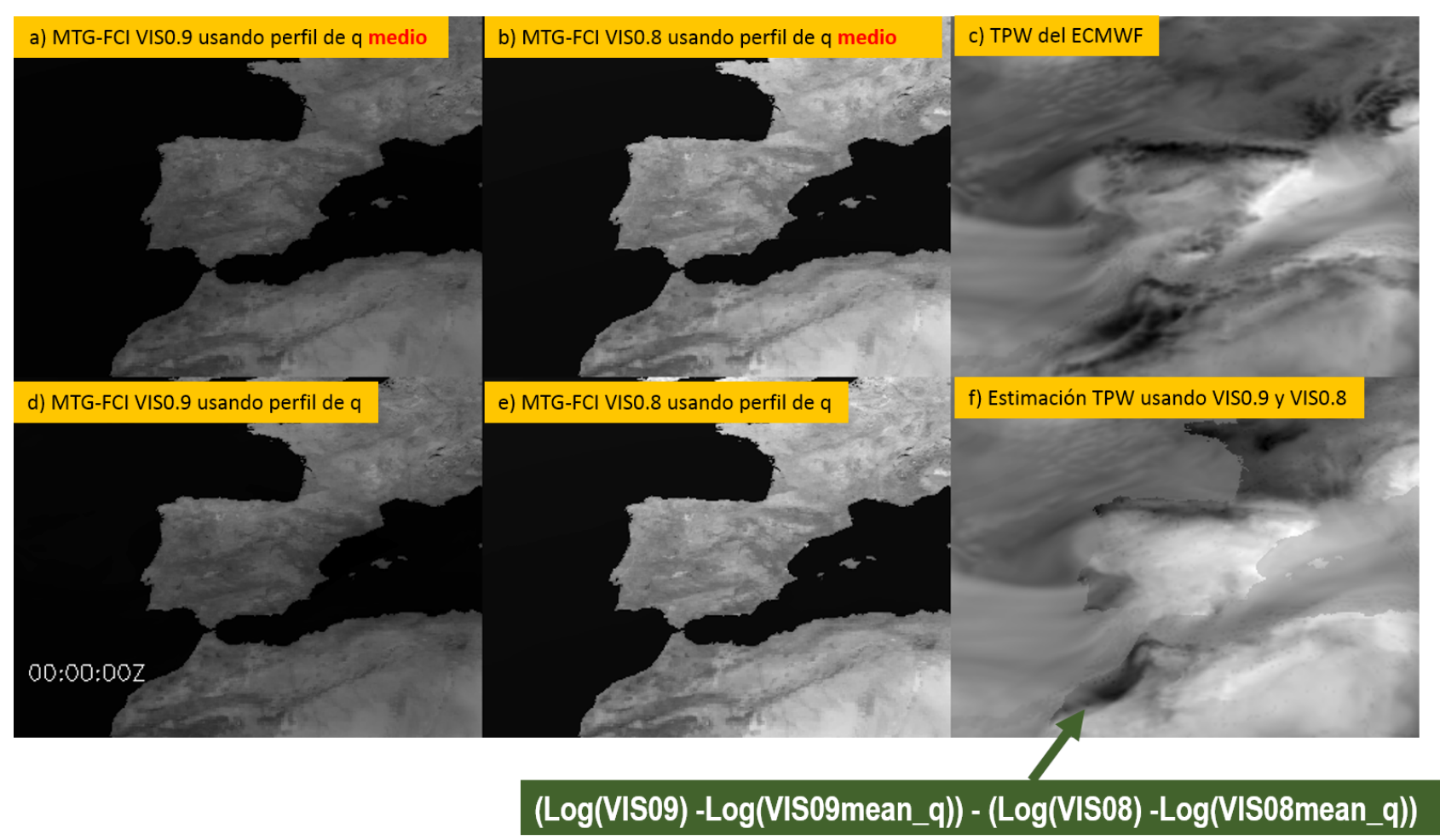

Figura 6. a) Imagen sintética FCI-VIS0.9 usando perfil $q$ medio, b) imagen sintética FCI-VIS0.8 usando perfil $q$ medio, c) TPW del análisis ECMWF, d) sintética FCI-VIS0.9, e) sintética FCI-VIS0.8,

f) estimación TPW usando la fórmula en verde que aparece en la figura.

\subsection{Planes del NWC SAF para el detector de rayos MTG-LI}

Los productos de NWC SAF con el detector de rayos LI serán desarrollados por el Servicio Meteorológico de Rumania (integrado en CDOP-3 en el consorcio del NWC SAF). Más adelante varios algoritmos irán haciendo uso de los rayos como entrada. LI, al ser un instrumento óptico en órbita geoestacionaria, detecta rayos nube-nube y permitirá complementar a la red de rayos de AEMET que detecta principalmente rayos nube-tierra y extender la cobertura.

\section{DESCRIPCIÓN DE MTG-IRS Y PRODUCTOS DEL NWC SAF}

Si comparamos los canales infrarrojos disponibles en el instrumento FCI con los equivalentes de los satélites HIMAWARI y GOES-R vemos que FCI no dispone ni del tercer canal vapor de agua ni del tercer canal en la ventana dividida. Pero esta aparente debilidad de MTG-I FCI será ampliamente compensada cuando sea lanzado el satélite complementario MTG-S. 


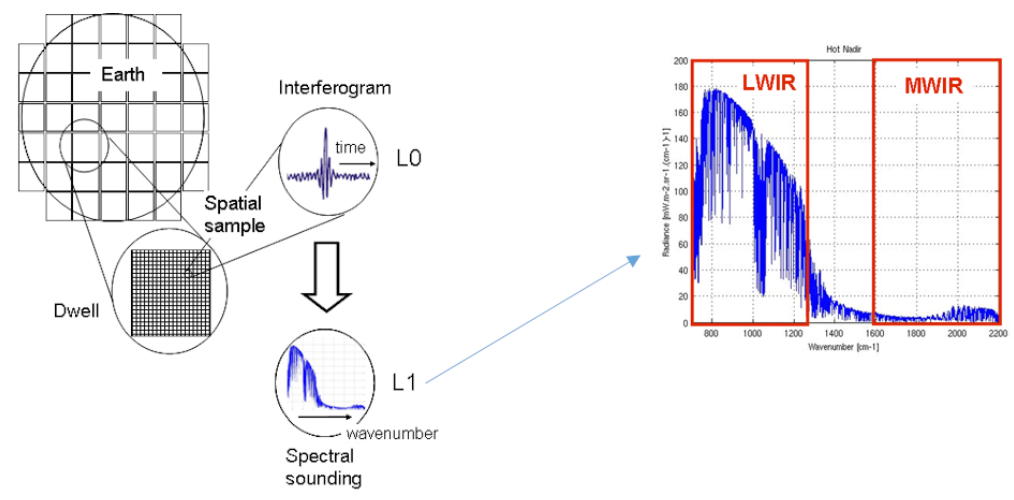

Figura 7. Generación del espectro en bandas LWIR y MWIR desde el interferograma.
MTG-S llevará a bordo el instrumento IRS. IRS está basado en el interferómetro de Michelson y será el primer sondeador hiperespectral IR operacional en órbita geoestacionaria. Como puede verse en la figura 7 , en cada píxel se obtiene el interferograma y después mediante la transformada de Fourier se genera el espectro con las radiancias. La forma de exploración de IRS se realiza mediante lo que se conoce como $d w e l l$; durante unos segundos se realiza el movimiento de los espejos del interferómetro sobre la región fija del $d$ well y se generan los interferogramas con resolución espacial de 4 km usando un array de $160 \times 160$ detectores (equivalente a una región de unos $640 \times 640 \mathrm{~km}$ en el punto subsatélite). El espectro con las radiancias se generará con resolución espectral de $0,600 \mathrm{~cm}^{-1}$ en dos bandas (MWIR y LWIR) dentro del segmento terrestre de EUMETSAT. La banda LWIR (Long Wave InfraRed) [700, $1210 \mathrm{~cm}^{-1}$ ] en el rango $(14,3-8,26 \mu \mathrm{m})$ y la banda MWIR (Mid Wave InfraRed) [1600, $\left.2175 \mathrm{~cm}^{-1}\right]$ en el rango $(6,25-4,6 \mu \mathrm{m})$. En total se dispondrá de unos 1800 canales.

Como puede verse en la figura 8 , después se realiza la observación del siguiente $d w e l l$ hasta cubrir cada región LAC. Se han establecido 4 regiones LAC y los $d$ well en la región LAC4 se observarán cada 30 minutos. En el resto de las LAC se realizarán al menos 3 secuencias consecutivas cada 30 minutos (para permitir la obtención de vientos) pero con intervalos de hasta varias horas dependiendo de la LAC.

Las altas prestaciones de MTG-I y MTG-S son posibles porque estarán estabilizados mediante tres ejes lo que permite aumentar el tiempo de observación. Esto también implica que la observación se realiza mediante $d w e l l s$ y la diseminación se realizará usando un fichero por cada $d w e l l$. En el caso de MTG-I los datos nivel 1 estarán reproyectados y navegados por EUMETSAT a la proyección geoestacionaria; pero en MTG-S solo se proporcionará las coordenadas de cada píxel y cada usuario tendrá que realizar la reproyec-

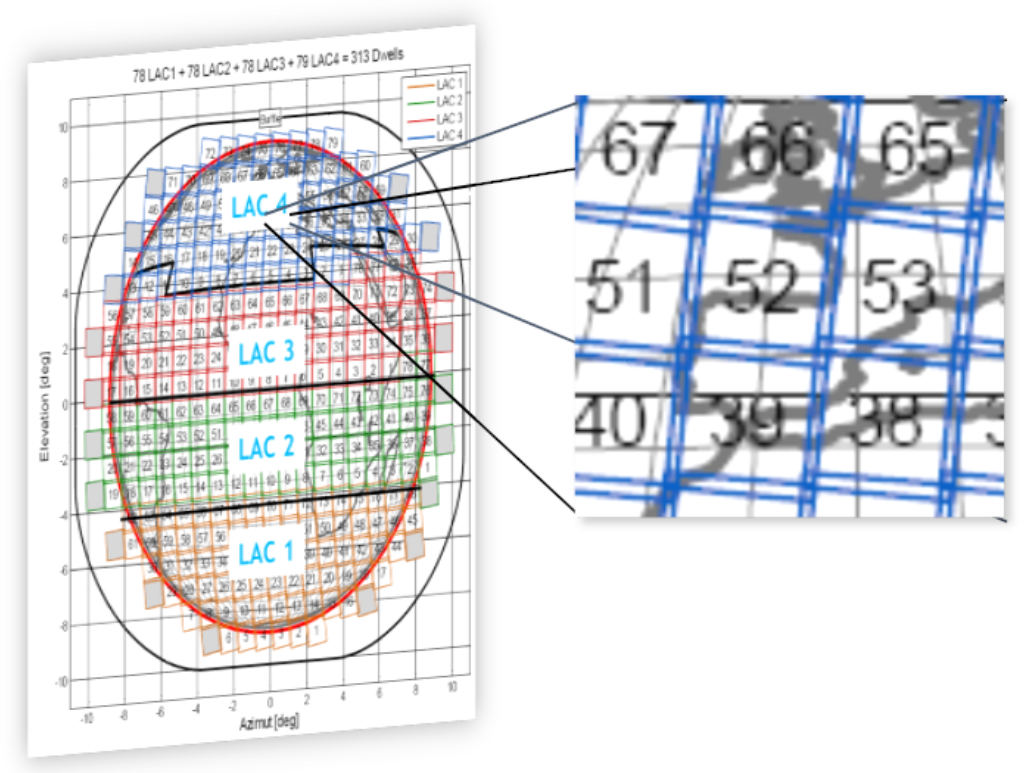

Figura 8. Mecanismo de exploración mediante $d w e l l s$ y necesidad de varios $d w e l l s$ para una región SAF de un usuario tipo. ción. Por tanto se necesitará software para montar las teselas que componen el mosaico de una región de interés de un usuario. Como este software tiene que ser ejecutado localmente (y además para cualquier producto que se propusiera habría que desarrollar igualmente el software de concatenación y reproyección de los $d w e l l s$ ) el NWC SAF ha propuesto para MTG-S IRS los siguientes productos y servicios: qIRS, sSHAI_ES y sSHAI. Estos productos y servicios serán preparados durante CDOP-3 y estarán disponibles como productos Día-2 durante la fase CDOP-4 (2022-2027); véase (MARTínez y CALBEt, 2016, 2018b). 


\section{1 qIRS (quick IRS)}

Debido al alto volumen de los datos nivel 1 de IRS no se diseminarán por EUMETCast satélite los espectros completos con las radiancias de todos los canales y se diseminarán 300 componentes principales (compresión con pérdidas). Para algunos centros (como el ECMWF) se prevé el uso de EUMETCast terrestre (internet de alta velocidad) para la diseminación de todos los canales sin pérdidas. Además, para cada $d w e l l$ se diseminará un fichero en formato NetCDF. Tras la recepción por el usuario, la primera actividad será la reconstrucción del espectro de BT desde las 300 componentes principales generándose un fichero por cada $d w e l l$ y escribiendo solo las BT seleccionadas por el usuario.

Como puede verse en la figura 8, para poder generar imágenes sobre las regiones de interés del usuario se necesitará un software que realice la lectura de los ficheros de los $d$ wells necesarios y la reproyección a las regiones definidas por el usuario. En la figura 9 puede verse como la resolución espacial de MTG-FCI es el doble de la resolución espacial de MTG-IRS. La región de interés y la proyección por defecto serán regiones definidas por el usuario en proyección MTG-FCI con resolución de 2 km (FCI) o en 4 km. Las BT de IRS reproyectadas podrán ser usadas para la generación de productos localmente con MTG-IRS; también en combinación con datos de MTG-FCI. Además, el usuario podrá generar más productos fuera del NWC SAF.

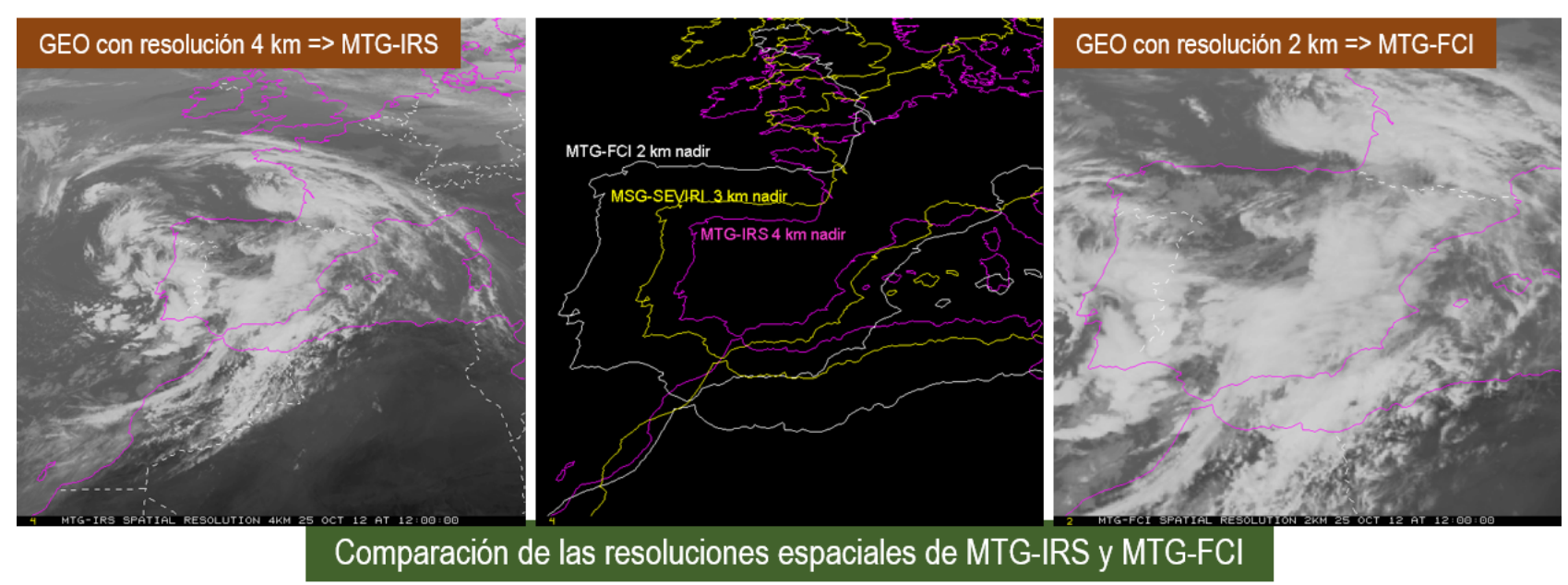

Figura 9. Imágenes para un satélite geoestacionario con resoluciones de 2, 3 y 4 km.

Aunque la mayor utilización de IRS será en predicción numérica las BT de IRS pueden ser usadas directamente también. La primera aplicación será la generación de imágenes con MTG-IRS en las regiones de interés para el usuario; por ejemplo imágenes RGB. En (MARTínEZ et al., 2010) puede verse el punto de partida. Usando el proceso descrito en la figura 10, se investigó qué canales sintéticos de IASI y de IRS son los más cercanos estadísticamente a cada uno de los canales sintéticos de MSG; con estos canales se generaron imágenes RGB análogas a las de MSG con las BT hiperespectrales sintéticas.

En (MARTínEZ Y CALBET, 2013) se mostraron las primeras imágenes RGB con datos reales de IASI análogas a las RGB de MSG. Se demostró que al menos las mismas imágenes RGB desarrolladas para MSG se podían generar con BT de instrumentos hiperespectrales de forma operativa. En la figura 11 se puede ver que es posible obtener imágenes de IASI RGB globales usando datos IASI de los dos METOP y se establecieron las bases de este tipo de procesos. Al necesitar usar varias decenas de archivos de IASI, para evitar desbordamientos de memoria, se vio la necesidad de la conversión de ficheros IASI HDF-5 a ficheros netCDF con estructura simplificada compatible con McIDAS-V con solo los canales a usar. Como puede verse en (MARTínez, 2015), el uso de estos ficheros acelera el proceso. 


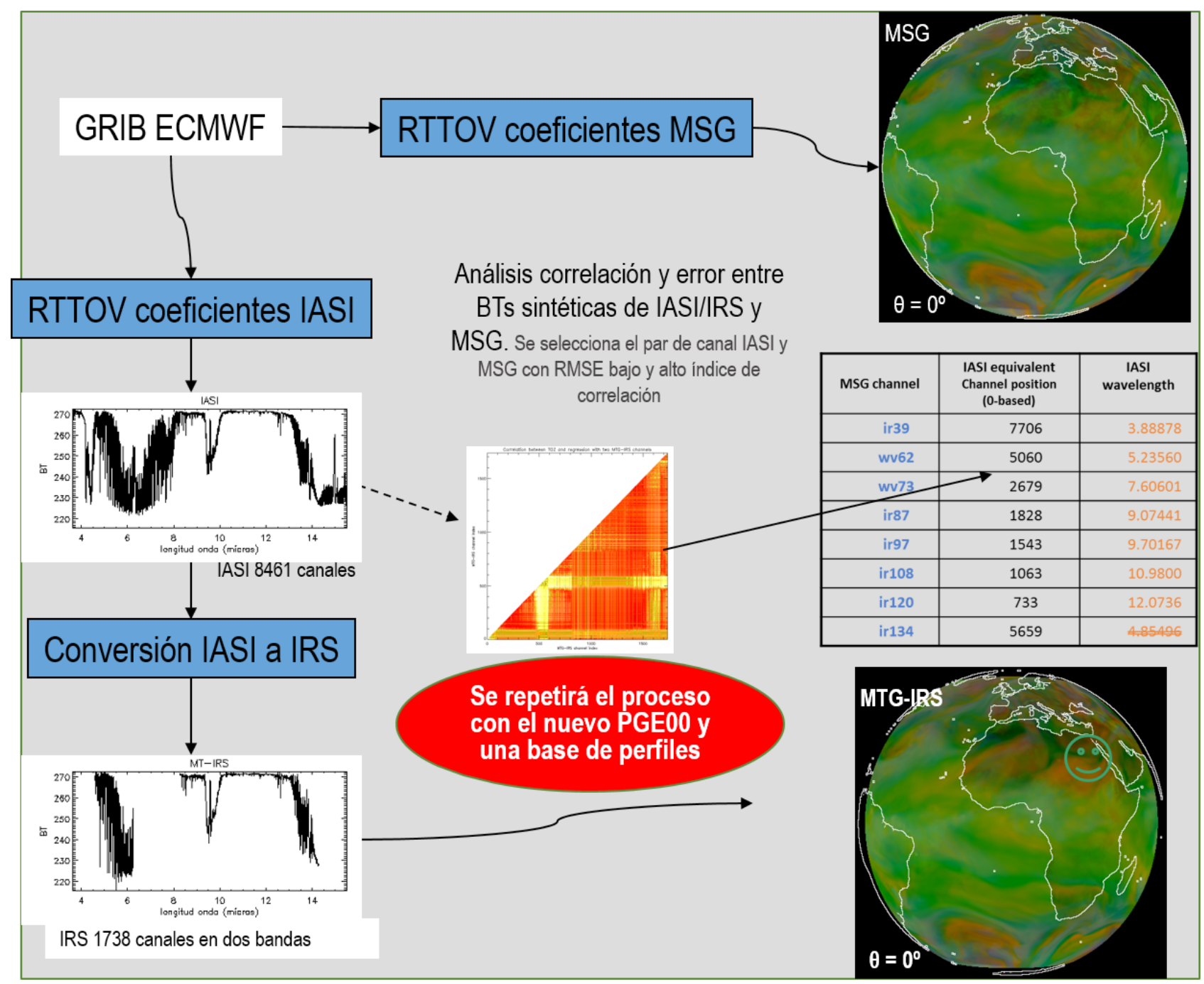

Figura 10. Proceso de generación de la primera imagen sintética RGB de masas de aire con IRS.

\section{3: RGB masas de aire con BTs reales de IASI}

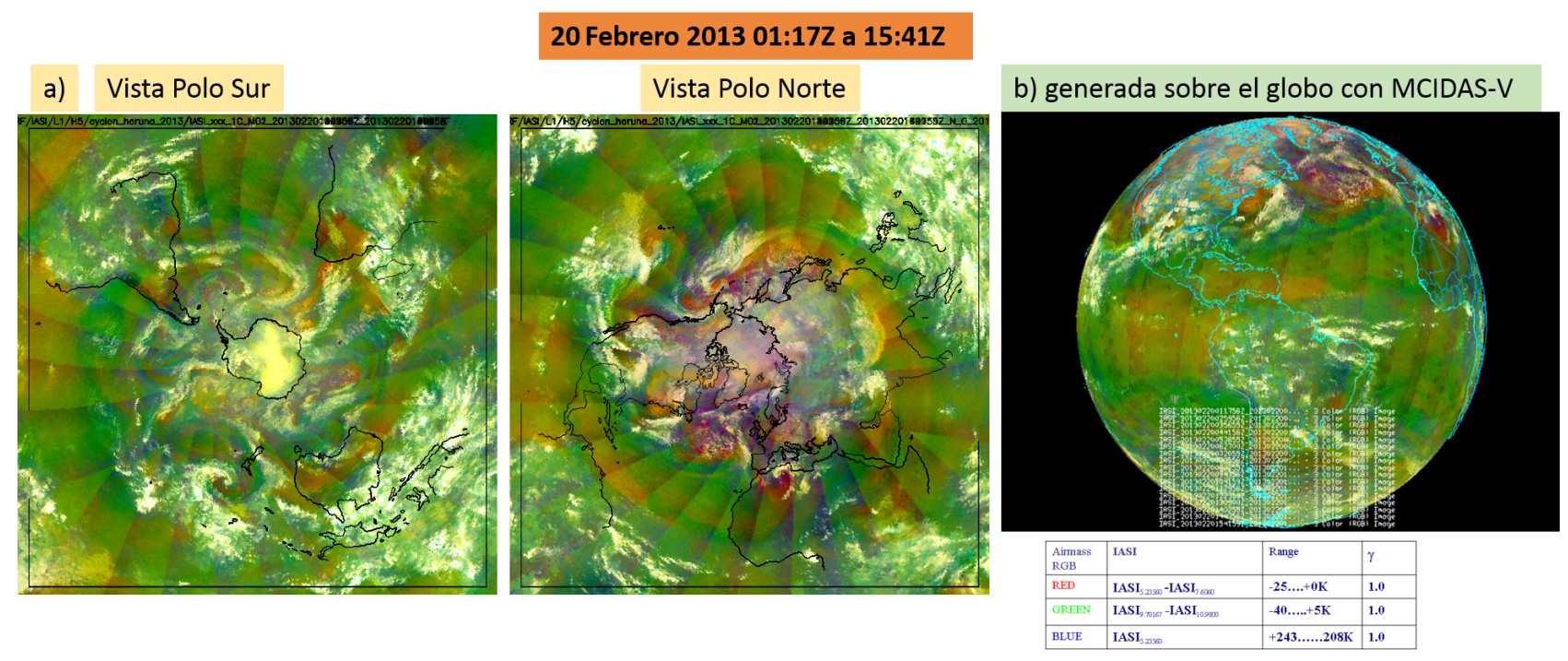

Figura 11. RGB de masas de aire con datos reales de IASI en METOP-A y METOP-B:

a) generadas con IDL sobre los polos usando gráficos transparentes;

b) generadas sobre el globo con MCIDAS-V (ver vídeo en hipervínculo). 
En la figura 12.a puede verse la sinergia entre la imagen RGB color verdadero de MODIS y la RGB de polvo con IASI en una tormenta de polvo en el Sahara; este tipo de actividades son las que podrán repetirse con las RGB de FCI e IRS. En la figura 12.b puede verse el uso de la RGB de polvo con IASI para monitorizar las cenizas volcánicas del volcán Cordón-Palhue.

a) Sinergia RGB "color verdadero" MODIS y RGB polvo de IASI

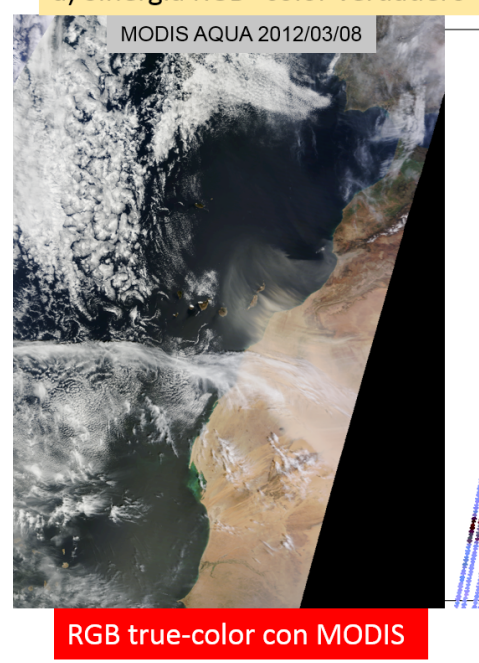

Tormenta de polvo 8 Marzo 2013

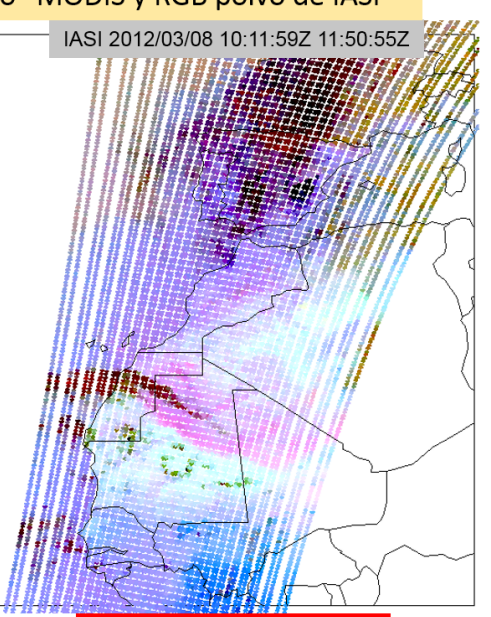

RGB de polvo con IASI

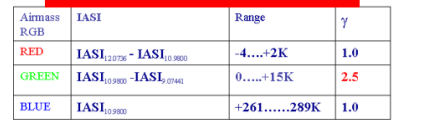

b) RGB IASI para detección cenizas volcánicas y $\mathrm{SO}_{2}$

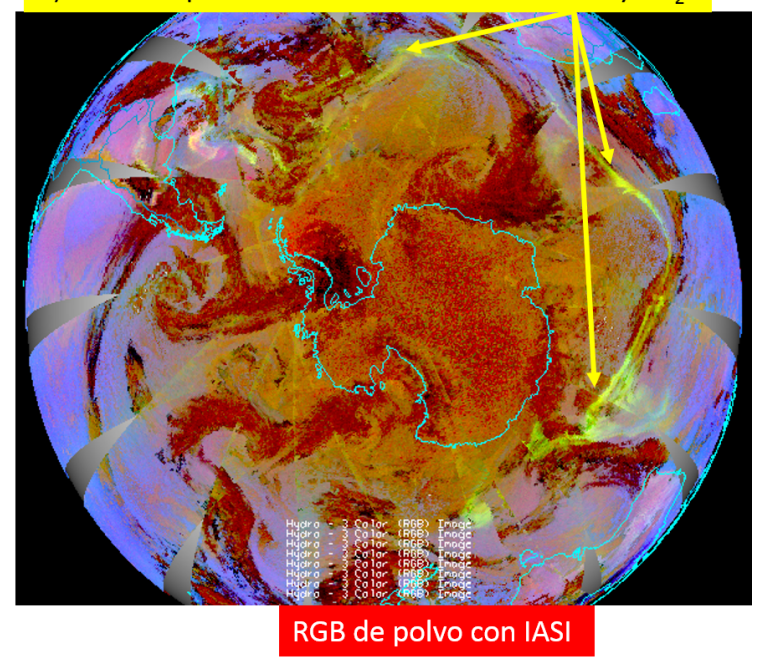

Erupción del volcán chileno Puyehue-Cordon Imágenes del 9 y 10 Junio 2011

Figura 12: a) RGB «color verdadero» de MODIS y RGB polvo con datos reales de IASI. b) RGB de polvo con IASI con las cenizas volcánicas de la erupción del volcán Cordón-Palhue.

En las figuras 13 y 14 pueden verse la comparación de imágenes reales y sintéticas de IASI generadas tras las últimas actividades realizadas. Las imágenes de IASI reales han sido creadas con McIDAS-V usando el último prototipo del software de qIRS; este realiza la lectura de ficheros netCDF de IASI nivel 1 del UMARF, reordena los 4 detectores de IASI y escribe en formato NetCDF compatible con McIDAS-V. Las imágenes sintéticas han sido generadas con la última versión de PGE00 que usa RTTOV-12.1 y como entradas GRIB del ECMWF en niveles híbridos con el perfil de nubosidad.

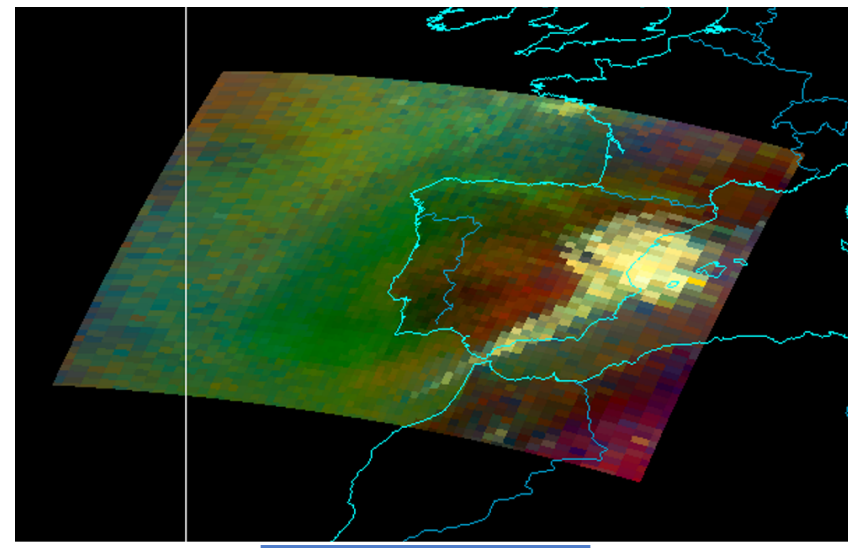

IASI real airmass RGB

IASI METOP-B Image

2016-08-10T10:32Z

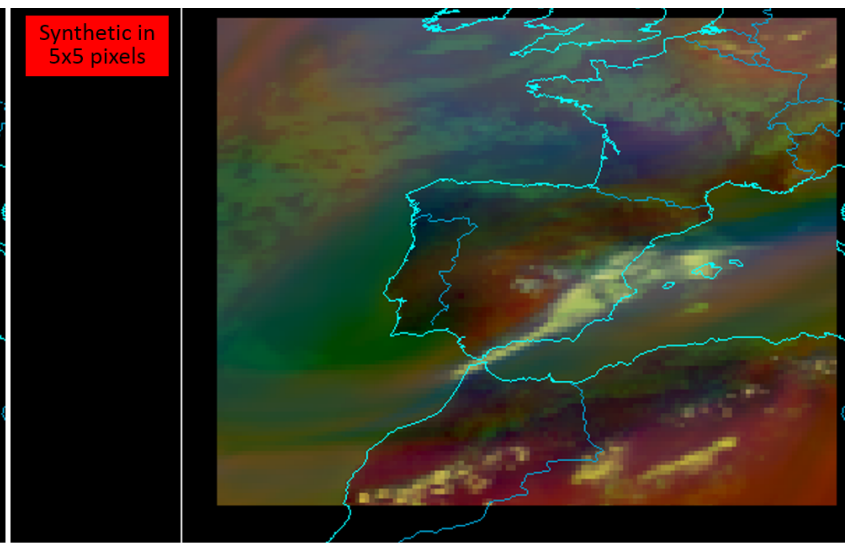

IASI synthetic PGEO0 airmass RGB

ECMWF 10 th August 2016122 $t+12$ from $10^{\text {th }}$ August 2016 run $00 Z$

Figura 13. Comparación de imágenes RGB real y sintética con ángulo cenital de un satélite geoestacionario en $0^{\circ}$ usando PGE00. 
En la figura 14 puede verse otra idea de uso imágenes de IRS propuesta en (MARTínEZ y CALBET, 2013) y en (MARTínEZ, 2015); la búsqueda de canales adecuados para generar una visión rápida y suave que permita ir penetrando cada vez más en la atmósfera desde canales en niveles altos sin nubes a niveles bajos con todas las nubes. Pueden verse las secuencias de imágenes reales y sintéticas en longitudes de onda seleccionadas en la banda de absorción de $\mathrm{CO}_{2}$; estas permiten ir penetrando cada vez más en la atmósfera y van apareciendo las nubes con estructura semejante en ambas. Al usar en la llamada a RTTOV el perfil de nubosidad las imágenes sintéticas con nubes, se podrá asignar un nivel en la imagen sintética (usando el nivel donde las nubes empiezan a aparecer en ese canal) y estimar el nivel de las nubes en las secuencias reales.
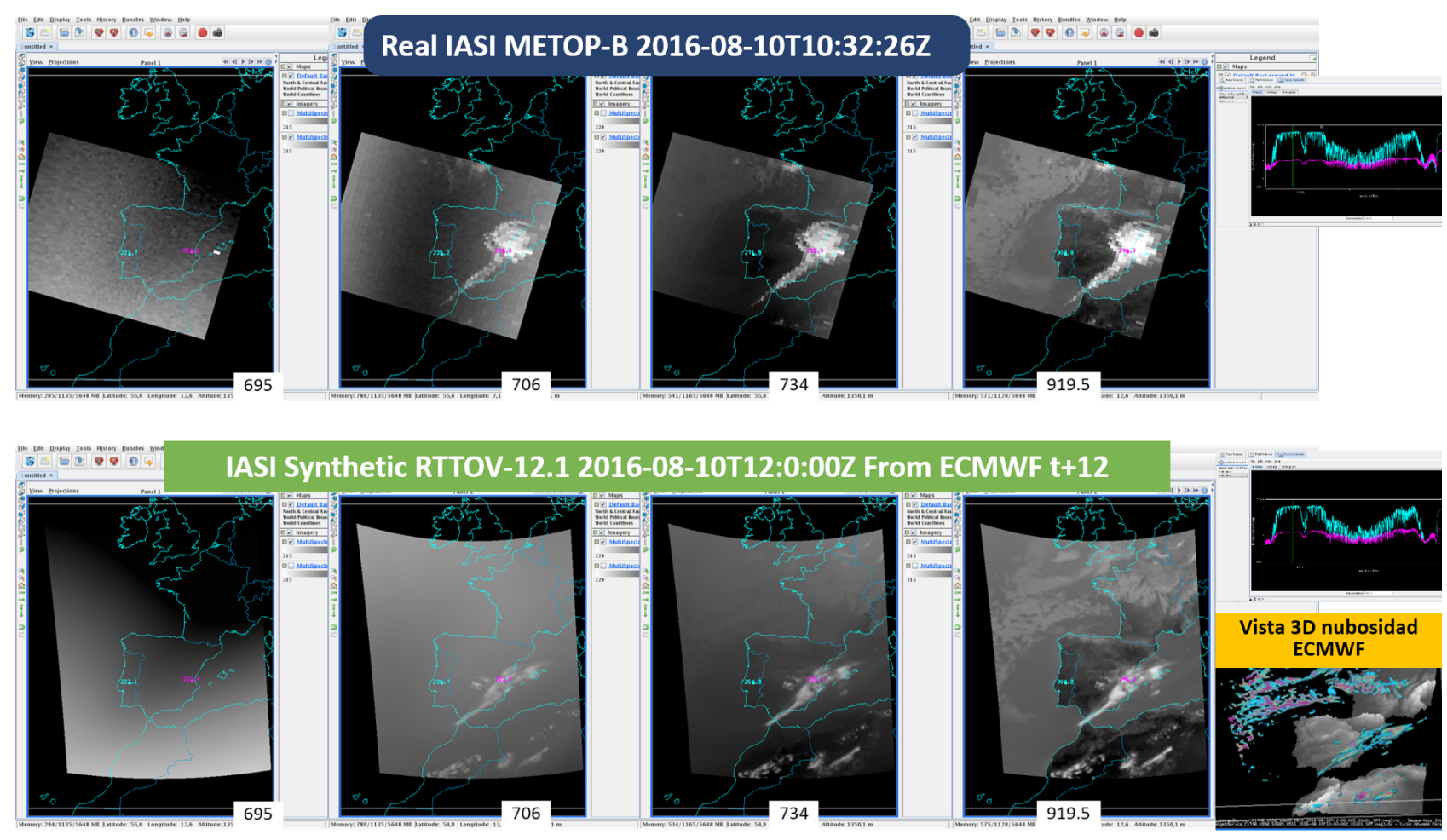

Figura 14. Secuencia de imágenes reales y sintéticas de IASI en banda de absorción de $\mathrm{CO}_{2}$ para ir penetrando cada vez más en la atmósfera.

\subsection{SSHAI_ES (sounder Satellite Humidity And Instability from EUMETSAT Secretariat)}

Este servicio proporcionará el soporte a los usuarios para el manejo de los productos nivel 2 de EUMETSAT Secretariat (ES) diseminados mediante EUMETCast. Se diseminarán los perfiles de temperatura, humedad y ozono obtenidos mediante la combinación de un algoritmo estadístico (Piece Wise Linear Regression; PWLR ${ }^{3}$ ) para generar el campo previo seguido de estimación óptima; en la versión Día-1 no utilizará un modelo numérico como campo previo. Los ficheros de cada $d w e l l$ diseminados no contendrán campos usados en nowcasting (TPW, LPW e índices de inestabilidad). El software sSHAI_ES realizará en primer lugar el cálculo de los mismos parámetros que en iSHAI (TPW, LPW e índices de estabilidad) en cada $d w e l l$. Hemos participado en varios experimentos llevados a cabo por EUMETSAT en los que ha sido necesario crear varios programas conversores (desarrollados en IDL y en GDL (versión GNU de IDL)) que sirven como prototipo. En la figura 15 se muestra un ejemplo de las salidas.

Para poder comparar los productos de iSHAI y s_SHAI_ES sobre las regiones de interés del usuario es necesaria la combinación y reproyección de los $d w e l l s$ necesarios; esto se realizará en un segundo paso. Se ha avanzado también en un prototipo para realizar la reproyección desde la proyección del satélite a la proyección geoestacionaria de las regiones del NWCSAF. En el prototipo (en su fase inicial) se ha evitado el 


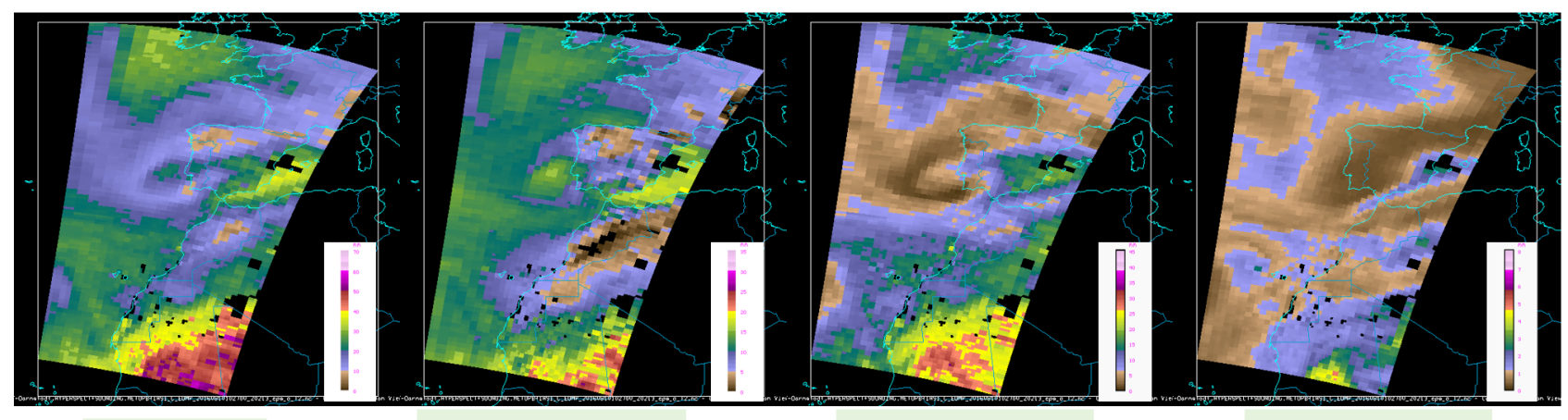

TPW

Precipitable Water in Boundary Layer

ML
$\begin{gathered}\text { Precipitable Water in Middle Layer } \\ \text { (850-500 ha) }\end{gathered}$

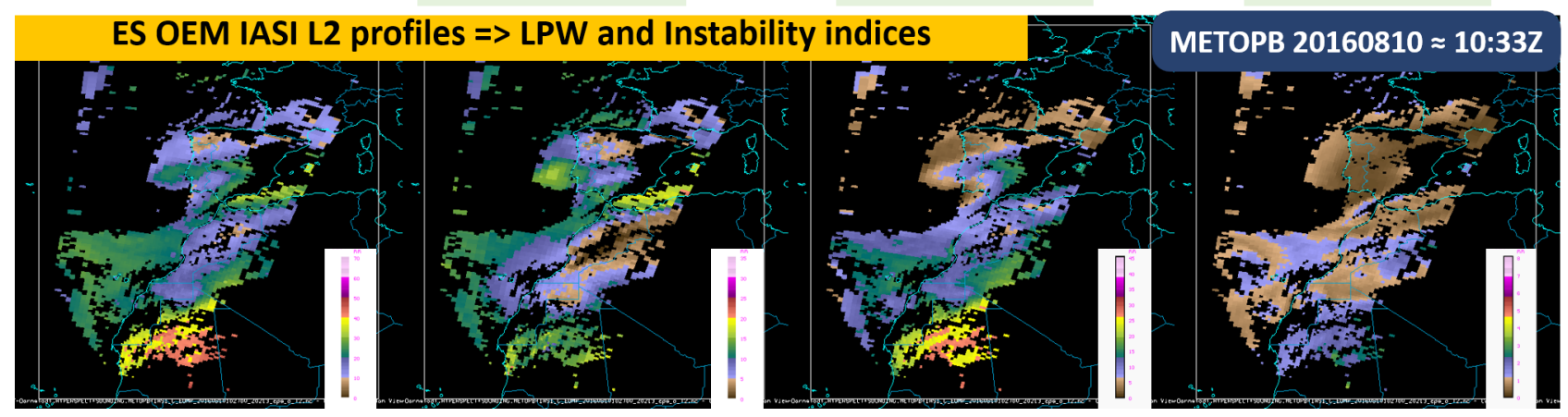

Figura 15. Conversión de ficheros de IASI nivel 2 de EUMETSAT a ficheros netCDF compatible con McIDAS-V con los mismos campos que iSHAI.

tener que calcular la distancia para cada punto de la región del SAF y todos los píxeles de IASI para después buscar el punto con la mínima distancia. Un ejemplo de la comparación del producto nivel 2 de IASI de EUMETSAT después de la reproyección con los de iSHAI y ECMWF puede verse en la figura 16.
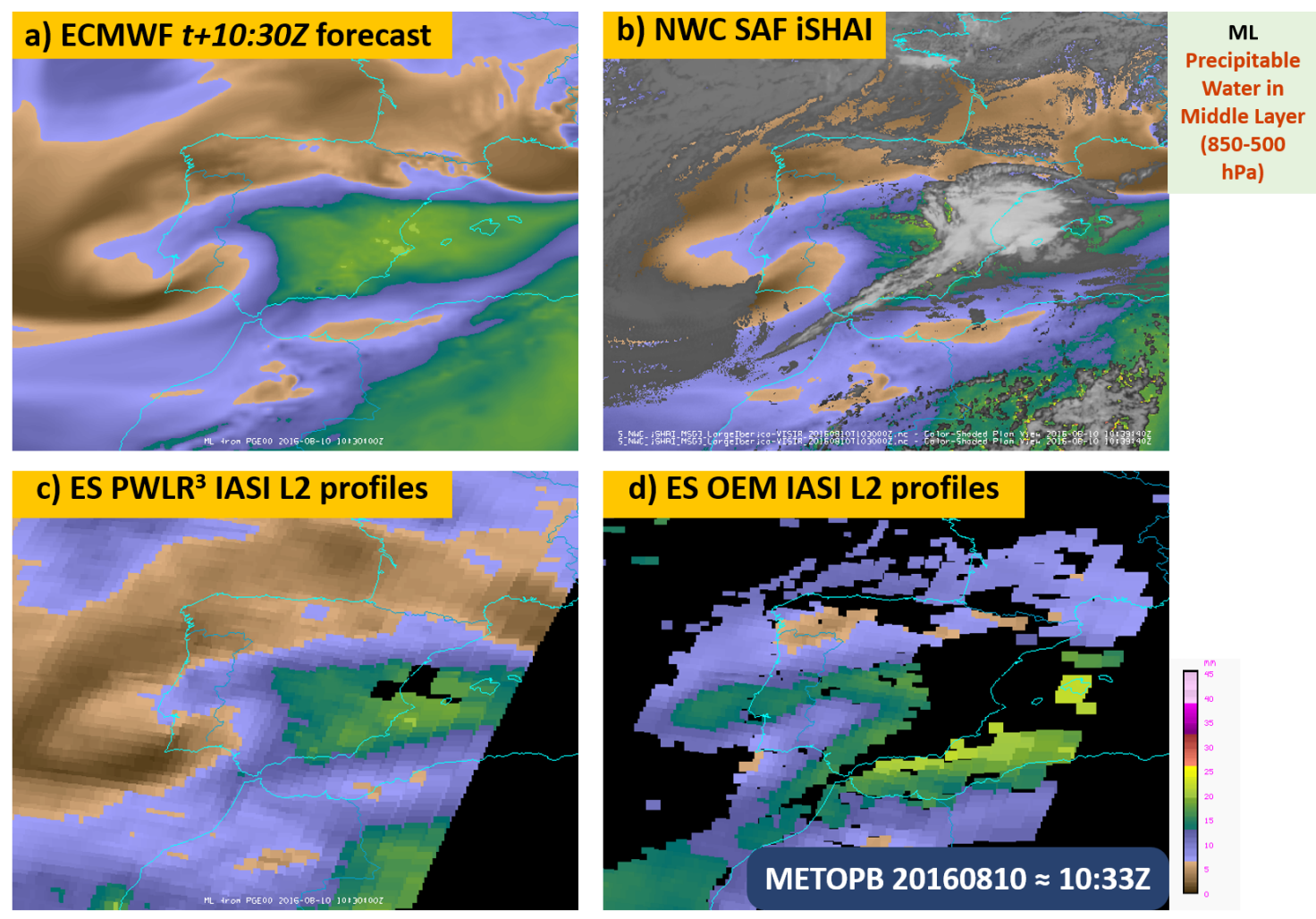

Figura 16. a) ML ECWMF, b) ML iSHAI usando $t+10: 30$, c) ML PWLR ${ }^{3}$ de IASI nivel 2 de EUMETSAT, d) ML estimación óptima (OEM) IASI nivel 2. 

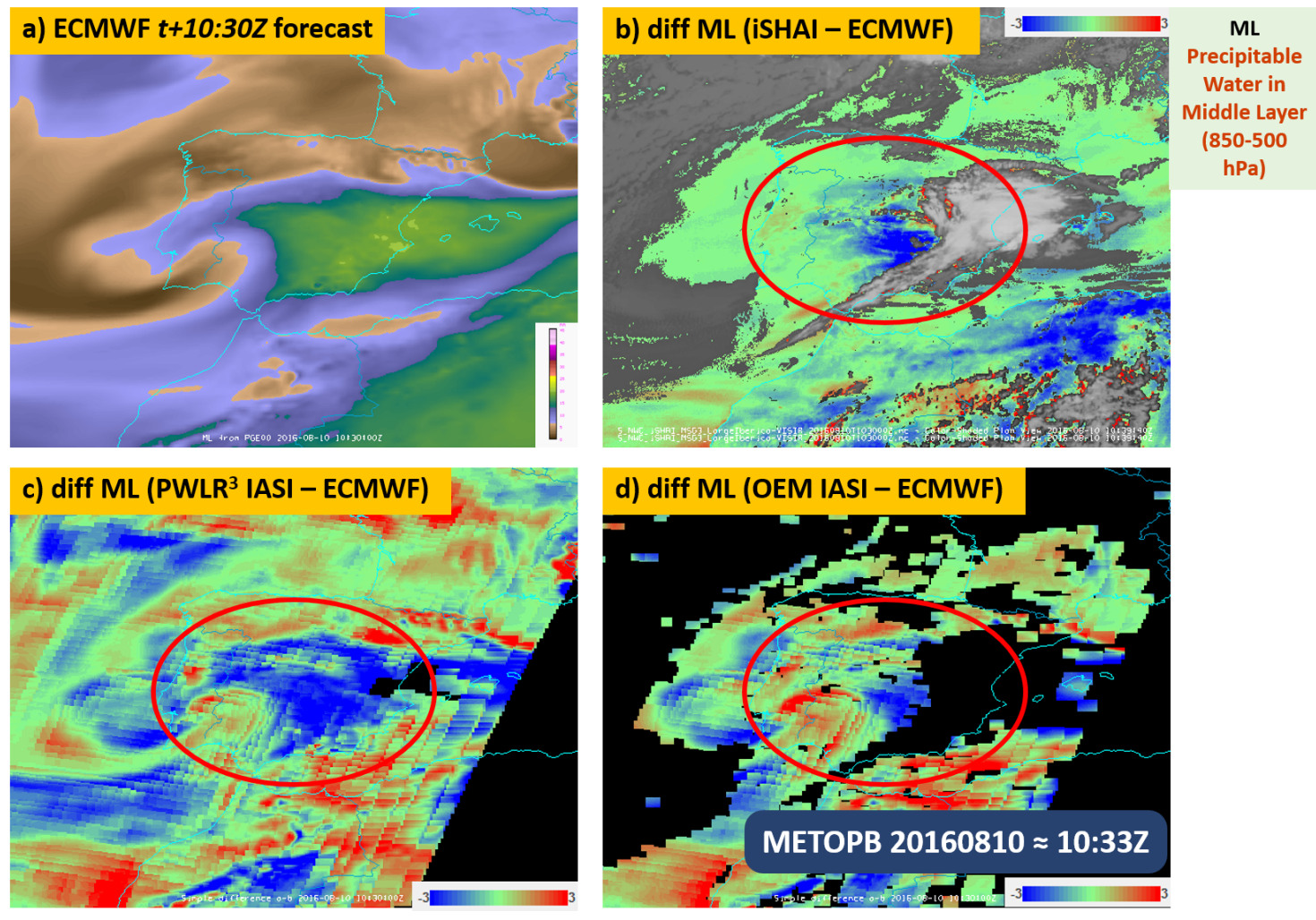

Figura 17. a) ML ECWMF, b) diferencia ML entre iSHAI y ECMWF, c) diferencia ML entre $\mathrm{PWLR}^{3} \mathrm{y}$ ECMWF, d) diferencia ML entre OEM y ECMWF.

En la figura 17 puede verse cómo el campo diferencia entre los campos ML calculados con el ECMWF y EUMETSAT (no usa modelo numérico como campo previo) concuerda con el campo de diferencia de ML de iSHAI generado con el $t+10: 30 \mathrm{Z}$ en la región marcada por un círculo rojo y corroborado después por el análisis del ECMWF; véase (MARTínEZ y CALBET, 2018a).

\subsection{Producto SSHAI (local sounder SHAI from IRS) generado localmente}

sSHAI calculará perfiles de $T, q$ y ozono usando como entrada principal las BT resultado de la reconstrucción de los espectros en el servicio quickIRS para los $d w e l l s$ necesarios para la región definida por el usuario. sSHAI puede utilizar además como campo previo un modelo numérico proporcionado por el usuario (por defecto el usado para iSHAI con MTG-FCI). El uso como campo previo del modelo numérico proporciona información adicional sobre la estructura en niveles bajos.

Como sSHAI se ejecutará localmente utilizará un algoritmo estadístico como Kernel Ridge Regression (KRR) o una regresión no lineal semejante a las usadas en iSHAI con FCI (MARTínEz y Calbet, 2018a). Al disponer en IRS de unos 1800 canales (o 300 PC), frente a 5 canales en MSG, se pueden obtener estimaciones de mejor calidad y en píxeles parciamente nubosos. Además, se puede usar la máscara de nubes generada con MTG-FCI para identificar píxeles parcialmente nubosos. En la figura 18 puede verse la salida de un prototipo de sSHAI sin usar como campo previo un modelo numérico. Utilizando los perfiles generados se calcularán los mismos parámetros que en iSHAI y se escribirán en formato netCDF con la misma estructura que en iSHAI, sSHAI_ES y NWP PGE00.

Después se realizará la combinación y reproyección de los $d$ wells necesarios a la región de interés del usuario. Con software adecuado (como McIDAS-V) se podrán realizar operaciones como cortes verticales de las diferencias entre las distintas salidas y determinar cuál es el valor añadido aportado por cada uno de los distintos algoritmos. 


\section{SSHAI IASI METOPB $20160810 \approx 10: 33 Z$}
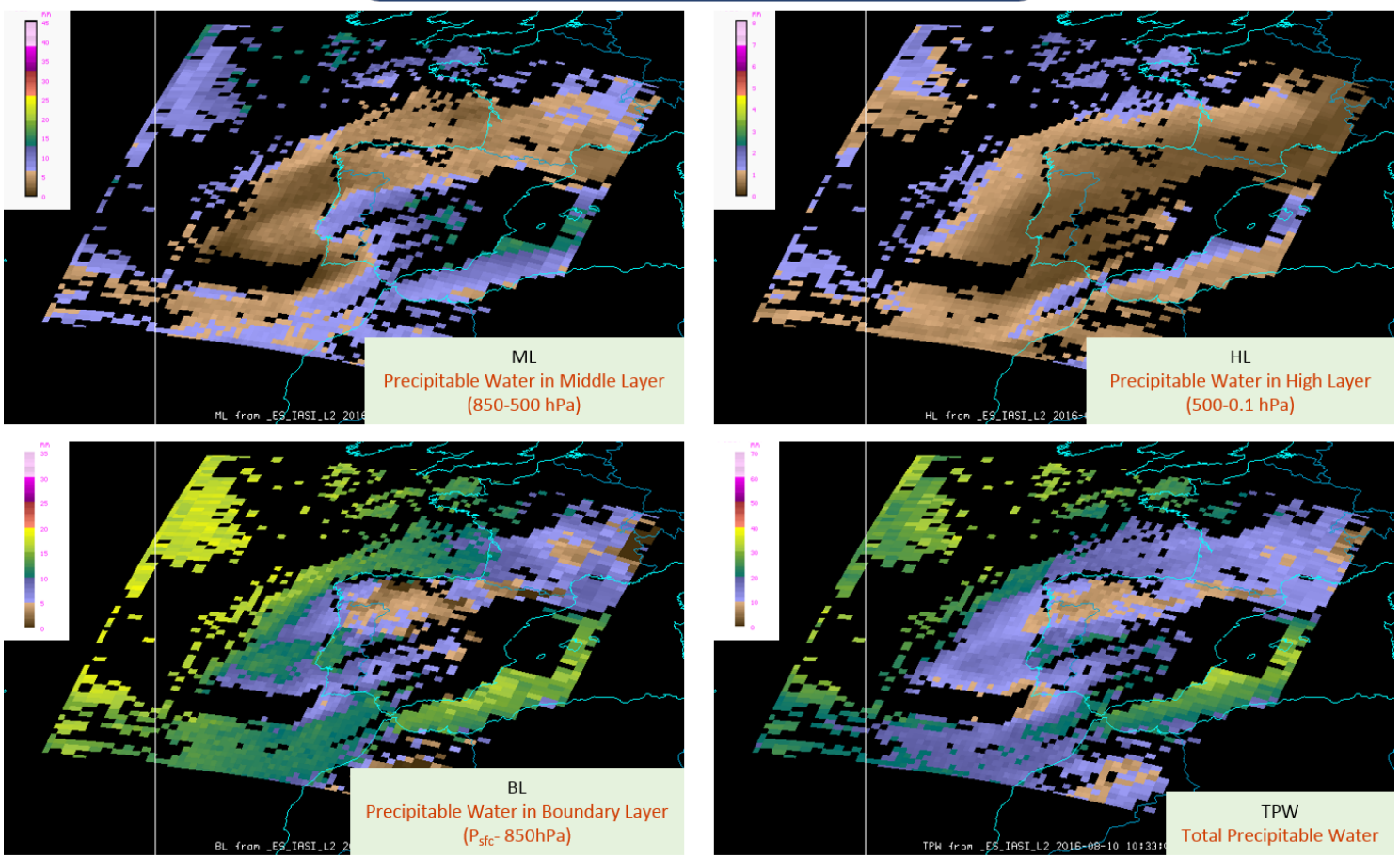

Figura 18. sSHAI con prototipo KRR sin uso de first-guess (X. CALbet y N. Peinado).

\section{CONCLUSIONES}

El software del NWC SAF cubrirá en primer lugar la necesidad de una herramienta de reproyección y concatenación de los $d w e l l$ individuales en los que se realiza la observación y diseminación de MTG para obtener productos sobre una región de interés para el usuario. De este modo tanto imágenes como productos de MTG-FCI, MTG-IRS y MTG-LI serán manejados por el NWC SAF.

En segundo lugar, el software del NWC SAF generará productos localmente usando los datos de MTG-FCI, MTG-IRS y MTG-LI y modelos numéricos del usuario. El uso de PGE00 y los datos reales de otros satélites como sustitutos de FCI (Himawari y GOES-R) e IRS (IASI) permitirá avanzar en el desarrollo de nuevos productos. Para mejorar la interoperabilidad y sinergias entre las distintas salidas uno de los puntos clave es generar todos los productos en formatos con estructuras compatibles con herramientas de libre distribución. El objetivo principal es poder explotar las sinergias y explorar las diferencias con los distintos productos.

\section{REFERENCIAS}

Martínez, M. A.; CAlbet, X., 2018a. Uso de iSHAI y PGE00 para la monitorización de situaciones preconvectivas. Actas del Sexto Simposio Nacional de Predicción (Memorial Antonio Mestre), Madrid.

Martínez, M. A.; CAlbet, X., 2018b. iSHAI and PGE00 as key tools in pre-convection. 2018 Convection Working Group Workshop in Ljubljana, Slovenia. En línea en: pptx o pdf con bucles en NWCSAF web.

Martínez, M. A.; CALBET, X., 2016. NWCSAF/GEO clear air product version 2016. Evolution to the MTG era. Proc. of 2016 EUMETSAT Satellite Data User's Conference, Darmstadt, Germany. En línea en: link.

Martínez, M. A., 2015: MSG Clear Air Products. Evolution to the MTG era. En línea en: link. 
Martínez, M. A.; CALbet, X., 2013. Innovative ideas for using the hyperespectral level 1 data of the next geostationary MTG-IRS in nowcasting. Proc. 2013 EUMETSAT Conference, Viena. En línea en: link.

Martínez, M. A.; Calbet, X., Prieto, J., Tuemkes, S., 2010. Use of synthetic RGB images in training. Proc. of the 2010 EUMETSAT Satellite Conference, Córdoba, Spain. En línea en: link. 